\title{
The comparison of urodynamic findings in women with various types of urinary incontinence
}

\author{
Mehmet Fatih Zeren, Mehmet Bilgehan Yüksel, Gokhan Temeltas \\ Urology Clinic, The State Hospital of Usak, Usak (MFZ) and Department of Urology, Faculty of Medicine \\ Celal Bayar University (MBY, GT), Manisa, Turkey
}

\section{ABSTRACT}

Purpose: We aimed to determine the differences of the urodynamic findings of mix urinary incontinence (MUI), urge urinary incontinence (UUI), and stress urinary incontinence (SUI), and to evaluate the urodynamic findings in different groups by using bladder sensitivity index (BSI).

Materials and Methods: The data of 99 patients who underwent urodynamic testing related to the suspicion of SUI, UUI or MUI were analysed. This analysis included a retrospective evaluation of patients' cards, voiding diaries, and urodynamic reports. At filling cystometry, the parameters of first sensation of bladder filling (FSBF), first desire to void (FDV), strong desire to void (SDV), and bladder capacity $\left(\mathrm{V}_{\max }\right.$ ), which were related to the bladder sensation, were determined. Subsequently, uroflowmetric findings were recorded during bladder emptying. BSI was defined as the ratio of $\mathrm{V}_{\max } /$ FDV. These results were statistically compared among the goups.

Results: The sample included 35(35.5\%) MUI, 33(33.3\%) UUI and 31 (31.1\%) SUI. The mean ages were similar in all groups $(\mathrm{P}=0.868)$. The mean FSBF, FDV, SDV and Vmax values were significantly different among groups $(\mathrm{p}=0.004, \mathrm{p}<0.001, \mathrm{p}<0.001, \mathrm{p}$ $<0.001$ respectively). Nevertheless, there was no statistically significant difference among the mean daily voiding accounts $(\mathrm{P}=0.005)$. Although the mean maximum flow rate $\left(Q_{\max }\right)$ values were similar $(P=0.428)$, the mean maximum detrusor pressure $\left(\right.$ Pdet $\left._{\max }\right)$ values were significantly different $(\mathrm{P}=0.021)$. The mean BSI values showed no significant differences $(\mathrm{P}=0.097)$.

Conclusions: It was concluded that while the use of urodynamic testing could contribute to the management of urinary incontinence, the indexes including BSI requere more detailed and comprehensive studies.

\section{ARTICLE INFO}

Key words:

Urodynamics; Urinary

Incontinence

Int Braz J Urol. 2014; 40: 232-9

Submitted for publication: July 16, 2013

Accepted after revision: November 24, 2013

\section{INTRODUCTION}

Urinary incontinence (UI) is a disorder with various symptoms of different severities and influences the women in all ages. Although it is not a life-threatening disorder, it can significantly affect the physical, psychological and social conditions of patients (1). While a great deal of attention has been given to possible treatment options for incontinence, the clinicians have also made a great effort to standardize the evaluation of these patients. The determination of the type and severity of UI, and its impact on patients' quality of life is an important issue, which affects the results of the treatment. Thus, it is a fact that the patients with UI must be evaluated by some diagnostic tools before treatment. Generally, these patients are evaluated by an initial detailed hystory, physical 
examination, routine urine test, and voiding diary. If required, non-invasive urodynamic testing and postvoiding residual urine measurement are performed. A multichannel urodynamic study is used in patients who are not diagnosed by previous analyses (2).

UI can be groupped according to ethiological factors, as stress urinary incontinence (SUI), urge urinary incontinence (UUI) and mixed urinary incontinence (MUI). Although the routinely use of urodynamic testing at initial evaluation of UI is not suggested by the current guidelines, it is supposed that urodynamic testing will provide some contributions to the clinicians to understand these disorders (3). Currently, the index values associated with bladder filling phase are still on debate, and bladder sensitivity index (BSI) is one of the most important (4).

In this study, we aimed to analyze the presence of possible differences among the urodynamic findings of MUI, UUI and SUI, and to evaluate the urodynamic characteristics in these groups by using BSI.

\section{MATERIAL AND METHODS}

The data of 99 patients who underwent urodynamic testing between October 2009 and March 2011 as a result of the suspicion of SUI, UUI or MUI in Celal Bayar University, Faculty of Medicine, Department of Urology were analysed. This analysis included a retrospective evaluation of patients' cards (that was completed previously to urodynamics), voiding diaries and urodynamic reports. The study protocol was approved by the Local Ethical Committee of Celal Bayar University, Faculty of Medicine.

The inclusion criteria to the study were:

1. The data of patients who underwent urodynamic investigation related to only the suspicion of SUI, UUI, or MUI.

2. The data of only the optimally performed urodynamic testing.

3. The previously recorded data of patients' cards, voiding diaries, and urodynamic reports without any lacks.
The exclusion criteria to the study included:

1. The history of previous incontinence surgery.

2. The history of previous or ongoing anticholinergic treatment.

3. The patients with different types of urinary incontinence, such as overflow incontinence, except for SUI, UUI and MUI.

4. The data of patients who underwent urodynamic investigation related to other reasons than SUI, UUI and MUI.

5. The presence of an illness that can cause urinary system dysfunction, such as multiple sclerosis, spinal tumor.

6. The presence of urinary tract infection.

7. The presence of an urinary fistula or diverticulum.

The data of age, medical history, the complaint at the time of the application, the findings of physical examination, voiding diary and urodynamic testing were determined. All of the urodynamic studies have been peformed by using an "Aymed" model, multichannel urodynamic device. To avoid false urodynamic evaluation, all patients micturated before the urodynamic investigation to empty the bladder. If the residual urine was present, it was emptied after the insertion of the urodynamic catheter. Subsequently, a pressure-flow study was performed. Eight Fr, three-way cystometry catheter that measured the bladder pressure and rectal balloon catheter that measured the abdominal pressure were placed in. During the filling phase, the infusion rate of isotonic $\mathrm{NACl}$ solution was $40 \mathrm{~mL} / \mathrm{sec}$. By filling of the bladder with isotonic $\mathrm{NACl}$ solution, the terms of first sensation of bladder filling (defined as the initially recognization of bladder filling, FSBF, $\mathrm{mL}$ ), first desire to void (the time of voiding desire that can be voluntarily retarded, FDV, $\mathrm{mL}$ ), strong desire to void (defined as the time of the presence of strong desire to void without any urges, SDV, $\mathrm{mL}$ ), and maximum bladder capacity $\left(\mathrm{V}_{\max }\right)$ were determined. Subsequently, the findings were recorded during bladder emptying $(5,6)$. The suggestions of 
International Continence Society (ICS) were used for technique and terminology of urodynamics (7). At filling phase, the presence of an increased bladder pressure $>15 \mathrm{cmH}_{2} 0$ and uninhibited detrusor contractions (DO) were noted. BSI was defined as the ratio of maximum bladder capacity and the bladder capacity during the occurrence of FDV $\left(\mathrm{V}_{\max } /\right.$ FDV).

All statistical analyses were performed by using SPSS 11.0. A p-value $<0.05$ was accepted as significant. A simplex variance analysis was used in tripple group comparisons. The double group comparisons were done by using independent sample t-test for large sample and Mann- Withney U test for small sample. Pearson correlation analysis was used for the correlation of parameters.

\section{RESULTS}

The study included the data of 99 patients: 33 (33.3\%) patients with UUI, 31 (31.1\%) patients with SUI and 35 (35.5\%) patients with MUI. The mean age was $49.06 \pm 15.9,50.6 \pm 11.1$ and 50.3 \pm 11.3 years, respectively. The mean ages were similar in all groups $(\mathrm{P}=0.868)$ (Figure-1). The mean FSBF values of patients with MUI, UUI and SUI were $134.4 \pm 31.7,136.8 \pm 33.8$ and 112.9 $\pm 24.5 \mathrm{~mL}$, respectively. The mean FSBF values were significantly different $(\mathrm{p}=0.004)$. While the mean FDV values were $232.6 \pm 44.5,195.2 \pm 36.5$ and $247.2 \pm 56.5 \mathrm{~mL}$, the mean SDV values were $334.02 \pm 64.8,273.3 \pm 61.5$, and $340.8 \pm 68.8 \mathrm{~mL}$, respectively. The mean FSBF and FDV values in

Figure 1 - The distribution of age according to the incontinence type.

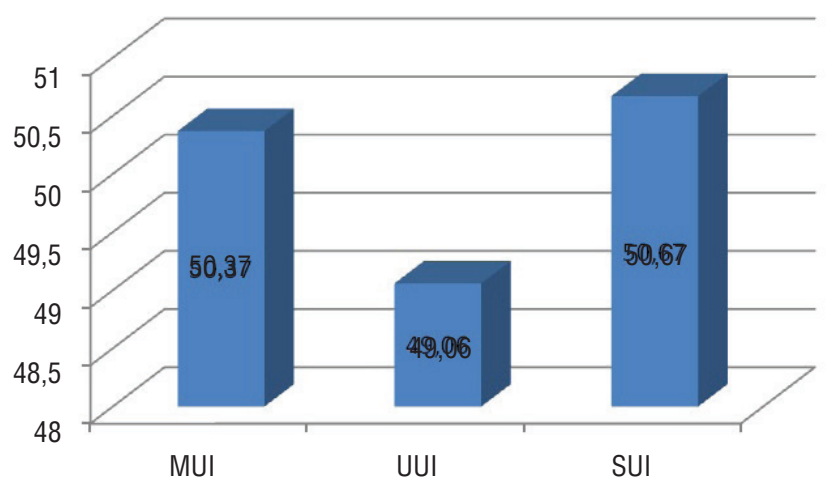

all groups were statistically significantly different ( $p<0.001$ in all). The mean bladder capacity was $420.4 \pm 58.6 \mathrm{~mL}$ in MUI group, $331.7 \pm 59.7 \mathrm{~mL}$ in UUI group, and $453.9 \pm 62.3 \mathrm{~mL}$ in SUI group. These results were also significantly different ( $\mathrm{p}$ $<0.001$ ). Nevertheless, no statistically significant difference was found among the mean voiding accounts $(10.9 \pm 4.06,12.2 \pm 4.02,9.1 \pm 2.6)(p=$ $0.005)$. The emptying phase showed that the mean maximum flow rate $\left(Q_{\max }\right)$ was $25.3 \pm 7.65 \mathrm{~mL}$ in MUI group, $24.1 \pm 5.49 \mathrm{~mL}$ in UUI group, and 26.6 $\pm 9.3 \mathrm{~mL}$ in SUI group. The mean value of maximum detrusor pressure $\left(\right.$ Pdet $_{\max }$ ) was $33.5 \pm 18.7$, $32.6 \pm 7.5$, and $25.03 \pm 9.9$, respectively. Although no statistically significant difference was found in the mean $Q_{\max }$ values $(p=0.428)$, the mean Pdet max values were significantly different $(\mathrm{p}=$ $0.021)$. The mean BSI values were $1.8 \pm 0.3$ in MUI group, $1.7 \pm 0.2$ in UUI group, and $1.9 \pm 0.4$ in SUI group. It was determined that there were no significant differences between the mean BSI values of 3 groups $(p=0.097)$. A detailed demonstration of these analyses is presented in Table- 1 .

In our sample, it was determined that 35 patients presented DO and 33 patients had no DO at urodynamic testing. When we looked at the distribution of these accounts according to the incontinence subgroups, it is observed that D0 was present in 15 patients in MUI group and 20 patients in UUI group. However, 20 patients in MUI group and 13 patients in UUI group had no DO. We have not determined a significant correlation between the patient accounts with and without DO in MUI and UUI groups $(\mathrm{P}=0.143)$. These results are clearly shown in Table- 2 . It has been determined that no significant difference was present among the BSI values in all three groups. However, we analyzed the relation between the BSI values of patients with and without DO in MUI and UUI groups. When we compared the BSI scores of patiets with DO with the scores of patients without DO in MUI and UUI groups, it was also found that BSI scores had no statistically significant differences ( $p=0.923, p=0.686$; respectively). The presence of DO had no impacts on the BSI scores of patients in MUI and UUI groups (Table-3). When the data were analyzed in paired groups, the comparison of daily voiding accounts between 
Table 1 - A detailed demonstration of the analysis of the parameters in all groups.

\begin{tabular}{|c|c|c|c|c|}
\hline & $\begin{array}{c}\mathrm{MUI} \\
\mathrm{n}=35\end{array}$ & $\begin{array}{c}\text { UUI } \\
n=33\end{array}$ & $\begin{array}{c}\text { SUI } \\
n=31\end{array}$ & \multirow[t]{2}{*}{ P-value } \\
\hline & Mean $( \pm$ SD) & Mean $( \pm$ SD) & Mean $( \pm$ SD) & \\
\hline Age & $50.3(11.3)$ & $49.06(15.9)$ & $50.6(11.1)$ & 0.868 \\
\hline Daily voiding account & $10.9(4.06)$ & $12.2(4.02)$ & $9.1(2.6)$ & 0.005 \\
\hline First sensation of bladder filling & $134.4(31.7)$ & $136.8(33.8)$ & $112.9(24.5)$ & 0.004 \\
\hline First desire to void & $232.6(44.5)$ & $195.2(36.5)$ & $247.2(56.5)$ & $<0.001$ \\
\hline Strong desire to void & $334.02(64.8)$ & $273.3(61.5)$ & $340.8(68.8)$ & $<0.001$ \\
\hline Bladder capacity & $420.4(58.6)$ & $331.7(59.7)$ & $453.9(62.3)$ & $<0.001$ \\
\hline$Q_{\max }$ & $25.3(7.6)$ & $24.1(5.4)$ & $26.6(9.3)$ & 0.428 \\
\hline Pdet max & $33.5(18.7)$ & $32.6(7.5)$ & $25.03(9.9)$ & 0.021 \\
\hline BSI & $1.8(0.3)$ & $1.7(0.2)$ & $1.91(0.4)$ & 0.097 \\
\hline
\end{tabular}

Table 2 - The distribution of patient accounts according to the presence of uninhibited detrusor contraction at urodynamic testing.

\begin{tabular}{cccccccc}
\hline & \multicolumn{7}{c}{ Incontinence Type } \\
\cline { 3 - 7 } & MUI & $\%$ & UUI & $\%$ & Total & $p$ - value \\
\hline \multirow{3}{*}{ D0 } & 20 & 60.6 & 13 & 39.4 & 33 & 0.143 \\
& No D0 & 15 & 42.9 & 20 & 57.1 & 35 & \\
\hline & D0 present & 35 & 51.5 & 33 & 48.5 & 68 \\
\hline
\end{tabular}

Table 3 - The comparison of bladder sensitivity index scores of the patients in mix and urge urinary incontinence groups according to the presence of uninhibited detrusor contraction.

\begin{tabular}{|c|c|c|c|c|c|c|}
\hline & & DO & $\mathrm{N}$ & Mean & $\mathrm{SD}$ & $p$ - value \\
\hline \multirow[t]{2}{*}{ MUI } & BSI & no & 20 & 1.8 & 0.3 & \multirow{2}{*}{0.923} \\
\hline & & present & 15 & 1.8 & 0.3 & \\
\hline \multirow[t]{2}{*}{ UUI } & BSI & no & 13 & 1.7 & 0.3 & \multirow{2}{*}{0.686} \\
\hline & & present & 20 & 1.7 & 0.2 & \\
\hline
\end{tabular}


MUI and UUI groups revealed that there were no statistically significant differences $(p=0.201)$. However, the comparison between SUI group and the groups of MUI and UUI showed that the daily voiding accounts in MUI and UUI groups were significantly higher than in SUI group $(p=0.037, p=$ 0.001 ; respectively). Although it was not determined a significant difference between the volumes of FSBF in MUI and UUI groups ( $p=0.768)$, FSBF occurred in higher volumes in SUI group than in other two groups. The patients in SUI groups felt the FSBF in later volumes $(p=0.003, p=0.002$; respectively). Moreover, FDV and SDV values in SUI group were significantly lower than in SUI and MUI groups ( $p<0.001$ in all). Nevertheless, no significant difference was found between the FDV and SDV values of MUI and SUI groups $\left(\mathrm{P}_{\mathrm{FDV}}=\right.$ $0.248, \mathrm{P}_{\text {SDV }}=0.679$; respectively). The comparison results of Vmax values among all groups showed that the $\mathrm{V}_{\max }$ in SUI group was the highest ( 453.9 $\pm 62.3 \mathrm{~mL}$ ), and $\mathrm{V}_{\text {max }}$ in UUI group was the lowest $(331.7 \pm 5.7 \mathrm{~mL})$. The $\mathrm{V}_{\max }$ values were significantly different in each other $(p<0.001, p=0.028, p$ $<0.001$; respectively). The results of the comparison of all parameters in paired groups are clearly shown in Table-4.

\section{DISCUSSION}

Since the demonstration of the anatomy of female pelvis and its contents, the impact of the structure of female pelvic organs and the anatomical supplies on the continence mechanism have been discussed. It is currently possible to explain UI by urodynamic testing. In current practice, it is important to determine the changes in the anatomical structures with their functional interactions in the diagnosis and treatment planning of UI (8). The measurement of the intensity of desire for micturition has attracted great interest for the determination of the severity of symptoms and the evaluation of treatment results in many of lower urinary tract disorders (9). In patients with overactive bladder $(\mathrm{OAB})$, the developement of an assessment scale and the evaluation of urgency, which is the most common complaint of $\mathrm{OAB}$ patients, is particularly important $(10,11)$. Urodynamic study is the standard technique used for the evaluation of bladder sensation $(7,12)$. Moreover, the voiding diaries, which are reliable and repeatable tests, can be used for the assessment of bladder sensation $(13,14)$. In this study, we aimed to evaluate the presence of possible differences among the urodynamic findings of MUI, UUI and SUI, and to analyze the urodynamic findings in these groups by using BSI.

When Wiskind et al. compared the urodynamic findings of patients with MUI and UUI, they found that the $\mathrm{V}_{\max }$ was $308 \mathrm{~mL}$ in UUI group and $396 \mathrm{~mL}$ in MUI. The cystometric Vmax was significantly higher in patients with MUI (15). In another study, it was reported that the comparison of urodynamic findings between healthy volunteers and UUI patients showed that the patients with UUI felt the FSBF, FDV and SDV in lower volumes and earlier than control group (5). In our study, we analyzed the urodynamic findings in three subgroups of incontinence including MUI, UUI and SUI with the aim of finding possible alterations in bladder sensation related to the type of incontinence. Some significant differences were determined in terms of FSBF, FDV, SDV and Vmax among all three groups. Our study revealed that while the lowest FDV $(195.2 \pm 36.5 \mathrm{~mL})$ and SDV $(273.3 \pm 61.5 \mathrm{~mL})$ values were in UUI group, the highest FDV $(247.2 \pm 56.5 \mathrm{~mL})$ and SDV $(340.8 \pm 68.8 \mathrm{~mL})$ values were observed in SUI group. However, while UUI group showed the lowest $V_{\max }(331.7 \pm 59.7)$, SUI group had the highest $\mathrm{V}_{\max }$ value $(453.9 \pm 62.3)$. These results are similar to the literature $(5,16)$. Nevertheless, contrary to the expectations, while the patients in UUI group had the highest FSBF value $(136.8 \pm 33.8 \mathrm{~mL})$, the lowest FSBF value $(112.9 \pm 24.5 \mathrm{~mL})$ was observed in SUI group. We thought that the sensitivity of FSBF was insufficient in the evaluation of bladder sensation. Thus, this unit should be analyzed by more detailed and prospective studies.

The comparison of the data in bladder diaries showed that daily voiding accounts in MUI, UUI, and SUI groups were significantly different. It was determined that the daily voiding account in UUI group had the highest result (12.2 $\pm 4.02)$. Nevertheless, the daily voiding account in SUI group was the lowest $(9.1 \pm 2.6)$. In a previous study, Chieh and et al. analyzed the urodynamic characteristics in patients with MUI and UUI. They reported that no significant difference was found between the daily voiding accounts of MUI and UUI groups (3). Furthermore, additional studies are present in the previous literature $(9,17)$. On the other hand, when we looked at the urodynamic findings regarding the frequency of DO 
Table 4 - The demostration of the comparison results of all parameters in paired groups.

\begin{tabular}{|c|c|c|c|c|c|}
\hline & Incontinence Type & $\mathrm{N}$ & Mean value $(\mathrm{mL})$ & SD & P-value \\
\hline \multirow{2}{*}{ Daily voiding account } & MUI & 35 & 10.9 & 4.06 & \multirow{2}{*}{0.201} \\
\hline & UUI & 33 & 12.2 & 4.02 & \\
\hline \multirow{2}{*}{ Daily voiding account } & MUI & 35 & 10.9 & 4.06 & \multirow{2}{*}{0.037} \\
\hline & SUI & 31 & 9.1 & 2.6 & \\
\hline \multirow{2}{*}{ Daily voiding account } & UUI & 33 & 12.2 & 4.02 & \multirow{2}{*}{0.001} \\
\hline & SUI & 31 & 9.1 & 2.6 & \\
\hline \multirow{2}{*}{ First sensation of bladder filling } & MUI & 35 & 134.4 & 31.7 & \multirow{2}{*}{0.768} \\
\hline & UUI & 33 & 136.8 & 33.8 & \\
\hline \multirow{2}{*}{ First sensation of bladder filling } & MUI & 35 & 134.4 & 31.7 & \multirow{2}{*}{0.003} \\
\hline & SUI & 31 & 112.9 & 24.5 & \\
\hline \multirow{2}{*}{ First sensation of bladder filling } & UUI & 33 & 136.8 & 33.8 & \multirow[t]{2}{*}{0.002} \\
\hline & SUI & 31 & 112.9 & 24.5 & \\
\hline \multirow{2}{*}{ First desire to void } & MUI & 35 & 232.6 & 44.5 & \multirow{2}{*}{$<0.001$} \\
\hline & UUI & 33 & 195.2 & 36.5 & \\
\hline \multirow{2}{*}{ First desire to void } & MUI & 35 & 232.6 & 44.5 & \multirow{2}{*}{0.248} \\
\hline & SUI & 31 & 247.2 & 56.5 & \\
\hline \multirow{2}{*}{ First desire to void } & UUI & 33 & 195.2 & 36.5 & \multirow{2}{*}{$<0.001$} \\
\hline & SUI & 31 & 247.2 & 56.5 & \\
\hline \multirow{2}{*}{ Strong desire to void } & MUI & 35 & 334.03 & 64.8 & \multirow{2}{*}{$<0.001$} \\
\hline & UUI & 33 & 273.3 & 61.5 & \\
\hline \multirow{2}{*}{ Strong desire to void } & MUI & 35 & 334.03 & 64.8 & \multirow{2}{*}{0.679} \\
\hline & SUI & 31 & 340.8 & 68.8 & \\
\hline \multirow{2}{*}{ Strong desire to void } & UUI & 33 & 273.33 & 61.540 & \multirow{2}{*}{$<0.001$} \\
\hline & SUI & 31 & 340.87 & 68.8 & \\
\hline \multirow{2}{*}{ Bladder capacity } & MUI & 35 & 420.4 & 58.6 & \multirow{2}{*}{$<0.001$} \\
\hline & UUI & 33 & 331.7 & 59.7 & \\
\hline \multirow{2}{*}{ Bladder capacity } & MUI & 35 & 420.4 & 58.6 & \multirow{2}{*}{0.028} \\
\hline & SUI & 31 & 453.9 & 62.3 & \\
\hline \multirow{2}{*}{ Bladder capacity } & UUI & 33 & 331.7 & 59.7 & \multirow{2}{*}{$<0.001$} \\
\hline & SUI & 31 & 453.9 & 62.3 & \\
\hline
\end{tabular}


in MUI and UUI groups, the frequency of DO in UUI group (57.1\%) was higher than it was in MUI group (42.9\%). But, this result was not found statistically significant. Similar results are present in the literature $(16,18)$. Yong-Yau lin et al. reported that the parameters, which demonstrated the voiding function, such as maximum flow rate, average flow rate and maximum detrusor pressure were similar in the study groups (16). In our study, no significant difference was found in terms of $Q_{\max }$ among all three groups ( $p=0.428)$. Although Pdetmax values in 3 groups were significantly different $(p=0.021)$, the comparison of Pdetmax values between MUI and UUI groups showed no significant difference $(\mathrm{p}=$ 0.807). It was supposed that the presence of significant difference in terms of Pdet ${ }_{\max }$ among all three groups was due to voiding in lower pressures of patients with SUI.

Currently, the nomograms such as Abram-Griffits and Schafer, and the indexes such as Bladder Outlet Obstruction Index and Bladder Contractility Index are used to objectively evaluate bladder emptying (19). Some studies also evaluate the filling phase of the bladder in an analytical plane. BSI, which was created by Al-Shukri et al. (4), is one of these studies. This index was proposed with the aim of increasing the accuracy of urodynamic diagnosis of patients with $O A B(4)$. This term is calculated by the proportion of Vmax to the bladder volume at the time of the occurrence of FSBF $\left(\mathrm{V}_{\max } / \mathrm{FSBF}\right)$. This novel urodynamic parameter demonstrates the severity of voiding desire from FSBF to the squeeze. Low BSI value means that the duration from FSBF to reach $\mathrm{V}_{\max }$ is short. A previous study revealed that BSI was lower in male patients than in female patients. It was also lower in patients with DO than in patients without DO $(p=0.001)$. Moreover, it was reported that this parameter was lower in patients who had higher frequency of urgency (4). In our study, the overall comparison of BSI values among three groups and also the separate comparison of BSI values only between MUI and UUI groups revealed no significant differences.

\section{CONCLUSIONS}

Sensation is an essential prerequisite for voluntary control of the bladder. Urodynamic studies are the standard technique in the evaluation bladder sensation. At filling phase of cystometry, it has been previously shown that various groups of patients had voiding desire in different bladder volume and severity. In our study, it was found that FSBF, FDV, SDV and $\mathrm{V}_{\text {max }}$, which were associated with bladder sensation, were significantly different in all three groups. Paired groups comparisons revealed that while the lowest FDV and SDV values were observed in UUI group, the highest FDV and SDV values were observed in SUI group. The presence of premature filling sensations and decreased bladder capacity in patients with MUI and UUI were demonstrated. Nevertheless, contrary to the expectations, while the patients in UUI group had the highest FSBF, the lowest FSBF value were seen in SUI group. On the other hand, no statistically significant difference was found among the BSI values and urodynamic data of patients in all three groups.

\section{ABBREVIATIONS}

$\mathrm{UI}=$ Urinary incontinence

MUI $=$ Mix urinary incontinence

UUI $=$ Urge urinary incontinence

SUI $=$ Stress urinary incontinence

BSI = Bladder sensitivity index

FSBF $=$ First sensation of bladder filling

FDV $=$ First desire to void

SDV = Strong desire to void

$\mathrm{V}_{\max }=$ Maximum bladder capacity

ICS $=$ International Continence Socieity

DO = Uninhibited detrusor contractions

Pdet $_{\text {max }}=$ Maximum detrusor pressure at maximum flow.

$\mathrm{Q}_{\max }=$ Maximum flow rate

$\mathrm{OAB}=$ Overactive bladder

\section{CONFLICT OF INTEREST}

None declared.

\section{REFERENCES}

1. International Continance Society: 4th International Consultation on Incontinence, Paris July 5-8, 2008. 
2. Lemack GE, Zimmern PE: Identifying patients who require urodynamic testing before surgery for stress incontinence based onquestionnaire information and surgical history. Urology. 2000; 55: 506-11.

3. Chou EC, Blaivas JG, Chou LW, Flisser AJ, Panagopoulos G: Urodynamic characteristics of mixed urinary incontinence and idiopathic urge urinary incontinence. Neurourol Urodyn. 2008; 27: 376-8.

4. Al-Shukri S, Kuzmin I: Bladder sensitivity index as a new urodynamic paramater in OAB patients. ICS 2009 Congress. Abstract $n^{0} 868$

5. Van Meel TD, Wyndaele JJ: Reproducibility of urodynamic filling sensation at weekly interval in healthy volunteers and in women withdetrusor overactivity. Neurourol Urodyn. 2011; 30: 1586-90.

6. Haylen BT, de Ridder D, Freeman RM, Swift SE, Berghmans $B$, Lee J, et al.: An International Urogynecological Association (IUGA)/International Continence Society (ICS) joint report on the terminology for female pelvic floor dysfunction. Neurourol Urodyn. 2010; 29: 4-20.

7. Abrams P, Cardozo L, Fall M, Griffiths D, Rosier P, Ulmsten $U$, et al.: The standardisation of terminology of lower urinary tract function: report from the Standardisation Sub-committee of the International Continence Society. Neurourol Urodyn. 2002; 21: 167-78.

8. Arıkan N: Kadınlarda Strese Bağlı İdrar Kaçırma. In: Anafarta K, Bedük Y, Arıkan N (ed.), Temel Üroloji; 2007; 3: Chap 11: 503-11.

9. Naoemova I, Van Meel T, De Wachter S, Wyndaele JJ: Does sensory bladder function during cystometry differ from that in daily life? A study in incontinent women. eurourol Urodyn. 2009; 28: 309-12.

10. Chapple CR, Artibani W, Cardozo LD, Castro-Diaz D, Craggs $M$, Haab $F$, et al.: The role of urinary urgency and its measurement in the overactive bladder symptom syndrome: currentconcepts and future prospects.BJU Int. 2005; 95: 335-40. Erratum in: BJU Int. 2005; 95: 924.

11. Brubaker L, Chapple C, Coyne KS, Kopp Z: Patient-reported outcomes in overactive bladder: importance for determining clinical effectiveness oftreatment. Urology. 2006; 68: 3-8.
12. De Wachter S, Wyndaele JJ: Frequency-volume charts: a tool to evaluate bladder sensation. Neurourol Urodyn. 2003; 22: $638-42$.

13. Naoemova I, De Wachter S, Wuyts FL, Wyndaele JJ: Reliability of the 24-h sensation-related bladder diary in women with urinary incontinence. Int Urogynecol J Pelvic Floor Dysfunct. 2008; 19: 955-9.

14. Naoemova I, De Wachter S, Wyndaele JJ: Comparison of sensation-related voiding patterns between continent and incontinent women: a study with a3-day sensation-related bladder diary (SR-BD). Neurourol Urodyn. 2008; 27: 511-4.

15. Wiskind AK, Miller KF, Wall LL: One hundred unstable bladders. Obstet Gynecol. 1994; 83: 108-12.

16. Lin $\mathrm{LY}$, Yeh $\mathrm{NH}$, Lin $\mathrm{CY}$, Sheu BC, Lin HH: Comparisons of urodynamic characteristics between female patients with overactive bladder andoveractive bladder plus stress urinary incontinence. Urology. 2004; 64: 945-9.

17. Lewis JB, Ng AV, O'Connor RC, Guralnick ML: Are there differences between women with urge predominant and stress predominant mixed urinary incontinence? Neurourol Urodyn. 2007; 26: 204-7.

18. Lin HH, Torng PL, Sheu BC, Shau WY, Huang SC: Urodynamically age-specific prevalence of urinary incontinence in women with urinary symptoms. Neurourol Urodyn. 2003; 22: 29-32.

19. Abrams P: Bladder outlet obstruction index, bladder contractility index and bladder voiding efficiency: three simpleindices to define bladder voiding function. BJU Int. 1999; 84: 14-5.

Correspondence address: Gokhan Temeltas, MD Department of Urology, Faculty of Medicine Celal Bayar University Uncubozköy Yerleşkesi, Merkez-Manisa/Turkey

Fax: + $90236233-8040$

E-mail: temeltasg@yahoo.com 